$$
\begin{aligned}
& \text { Then, } \quad X+Y=C-C l \text { in } \mathrm{KCl}(\mathrm{I}) \text {. } \\
& \text { and I.6486X+1.1957 } Y=W-\mathrm{KCl} \text { (2). }
\end{aligned}
$$

Solving for $Y$ find weight of $\mathrm{LiCl}$ (I.I957Y) in getting

the weight of $\mathrm{LiCl}$ from $Y$ a constant factor occurs, viz., I.I 957 I. $6486-$ I.I 957

it is not necessary to solve the equations.

The weight of $\mathrm{LiCl}$ is obtained as follows:

The $\mathrm{NaCl}$ equivalent of $\mathrm{C}-\mathrm{Cl}$ in $\mathrm{KCl}-(W-$ $\mathrm{KCl}$ ) multiplied by $2.64=\mathrm{LiCl}$ (3).

In order to test the accuracy of the method, $0.5000 \mathrm{~g}$. $\mathrm{NaCl}, 0.1000 \mathrm{KCl}$ and $0.0100 \mathrm{LiCl}$ were dissolved in water and diluted to roo cc. Spectroscopic tests showed a small quantity of potassium in the sodium chloride and a trace of sodium in the potassium chloride. This was immaterial since no lithium was shown in either the sodium chloride or potassium chloride nor was there any lithium in the calcium and magnesium chlorides used, but a small quantity of sodium and a trace of potassium were indicated in both. The results appear in Table II.

\begin{tabular}{|c|c|c|c|c|}
\hline \multirow{3}{*}{$\begin{array}{c}\text { Expt. } \\
\text { No. } \\
1 \ldots\end{array}$} & \multirow{2}{*}{\multicolumn{2}{|c|}{$\underset{\text { Present }}{\mathrm{KCl}}+\underset{\text { Fround }}{\mathrm{NaCl}}$}} & \multicolumn{2}{|c|}{$\underset{\text { LiCl }_{i \mathrm{C}}}{\text { LiThIUM }}$} \\
\hline & & & Present & Found \\
\hline & $\begin{array}{l}0.6100 \\
0.1525\end{array}$ & $\begin{array}{l}0.6098 \\
0.1569\end{array}$ & $\begin{array}{l}0.0100 \\
0.0025\end{array}$ & $\begin{array}{l}0.0106 \\
0.0025\end{array}$ \\
\hline
\end{tabular}

TABLE II-DFTERMINATION OF IITHIUM (RESULTS IN GRAMS)

The determination of lithium by this method is based upon two other definite determinations, potassium and chlorine, than which, in the hands of a skilful analyst and under the conditions of this method, no determinations are more accurate.

The only other factor affecting the accuracy of the method is an impurity in the weighed chlorides and under ordinary conditions this can result only from careless work or inexperience.

KENTUCKY AGRICULTURAL EXPERIMENT STATION LEXINGTON, KENTUCKY

\section{NITRATE DETERMINATIONS IN THE PRESENCE OF CHLORIDES}

By W. F. GERTCKE

Received February 2, 1917

The presence of chlorides in solutions on which nitrate determinations are to be made by the colorimetric method has long been a source of trouble to the analytical chemist. When nitrates are present in large amounts in solutions containing chlorides, determinations can very easily be made by the use of some of the reduction methods. Since, however, determinations for nitrates are often called for in solutions in which the amounts present are small, the quantity of ammonia produced by the reduction of the nitrates is of such magnitude as to often introduce a considerable error due to manipulation. It is under such conditions that the phenoldisulfonic acid method for nitrate determination is of ten employed, and in the absence of chlorides has been found to be sufficiently accurate and expeditious.

The effect of chlorides on nitrate determinations has been the subject of some study and has been duly reported in chemical papers. It is not deemed necessary to review here the literature on the subject. Suffice it to mention some of the results of the more important investigations.

(1) Chlorides cause losses of nitrates in determinations made by the phenoldisulfonic acid method.

(2) The loss of nitrates is not occasioned by the evaporation of the aqueous solution to dryness prior to the addition of the phenoldisulfonic acid.

(3) The loss of nitrates occurs when the phenoldisulfonic acid is added to the residue from the evaporated solution.

(4) The use of precipitants to remove the chlorides prior to the evaporation of the aqueous extract is recommended for accurate determinations.

(5) The use of calcium oxide and also calcium carbonate for the clarification of aqueous extracts, especially from soils, is recommended as a precipitant that is both efficient and non-interfering in the nitrate determinations.

The result of investigations, the conclusions of which have been briefly stated above, indicates that the presence of chlorides interferes with the reactions at a certain point in the process of the determinationsnamely, when the acid and dry salt containing the nitrates and chlorides come into contact. This results in the production of heat with the liberation of both chlorine and nitric acid, and thus interferes with the proper reaction of the latter with the phenoldisulfonic acid. Working on the principles enunciated by the investigators studying the colorimetric method of nitrate determinations, it occurred to me to try a method by which total evaporation of the nitrate. bearing solution to dryness could be obviated together with the necessity of adding the acid to the dry residue. Since the phenoldisulfonic acid reagent is a mixture of sulfuric acid and phenoldistlfonic acid it seems that the proper condition for the reaction of the phenoldisulfonic acid and the nitrates is in a sulfuric acid solution. By the addition of sulfuric acid to the nitratecontaining solution, a condition is brought about by which the complete evaporation to dryness of the aqueous solution may be obviated. When the phenoldisulfonic acid is then added to the acid-treated nitrate solutions some nitrophenoldisulfonic acid is formed. The complete reaction, however, will take place when the proper concentration of the solution has been attained. To attain this concentration and to employ temperature to accelerate the reaction of the nitrates and the phenoldisulfonic acid is the purpose of the partial evaporation to which the samples are sub. jected.

In making nitrate determinations one must remember that the theoretical reaction that elucidates the principle of the method goes to completion for quantitative determination only when an excess of phenoldisulfonic acid is used. Therefore, proper care should be taken in the preparation of the sample that the amount of nitrate present in the sample be neither too large nor too small to introduce measurable error due to the excessive or instufficient use of a given measure of the required acid reagents. Too much acid may seriously affect the accuracy of the determinations of samples in which the nitrate content is small, 
Vol. 9, No. 6

because of the action of the acid on the salts, and the increase in temperature involved.

The phenoldisulfonic acid reagent, as used in the laboratory, was prepared according to the Chamot method, $i$. e., an addition of fuming sulfuric acid is employed to insure pure phenoldisulfonic acid, free from all traces of phenolmonosulfonic acid.

The quantity of the sample used for analysis must be determined by the amount of nitrates in the aqueous solution. If the nitrate content is from I to 5 parts per million, a sample of at least $50 \mathrm{cc}$. should be used. To the sample, placed in a casserole or beaker, I. $5 \mathrm{cc}$. of concentrated sulfuric acid are added with constant stirring, then $2 \mathrm{cc}$. of phenoldisulfonic acid reagent. The casserole is then placed on a water bath, and most of the solution evaporated at the ordinary temperature of the steam bath. The last part of the evaporation, however, should be performed at a temperature preferably not over $70^{\circ} \mathrm{C}$.

The evaporation should proceed until the original solution is concentrated to a quantity varying from 6 or 7 to $\mathrm{I} 2$ or I $4 \mathrm{cc}$. The point to which evaporation must be continued is determined by the amount of nitrates in the original solution; for a low nitrate content a greater concentration of the original solution will be necessary. The proper concentration is determined by the color of the solution, which resembles that of phenoldisulfonic acid, slightly tinged with yellow. This condition will come, and final evaporation be attained at about the time that acid, due to the presence of chlorine, can be detected in the evaporating vapors. The important thing to observe in this modification is to bring about the final evaporation at a relatively low temperature. In no case should the solution be materially colored and turbid, although it may be somewhat darkened. A colored solution will result in an off tint when the alkali is added and will necessarily interfere with the accuracy of the determination. When the evaporation of the solution to its proper concentration has been accomplished, about $50 \mathrm{cc}$. or more of water are added; the solution is then neutralized with an alkali, care being taken to aroid the formation of excessive temperature when the acid is neutralized. The solution is then placed in the colorimeter and compared with a standard previously prepared, which may be made up according to the old method of total evaporation to dryness before adding the reagents, or according to the modification here reported, either of which will give the proper tint.

\section{RESULTS OBTAINED}

Table I indicates the feasibility of adding the phenoldisulfonic acid reagent before evaporation to dryness. Table II indicates the practicability of the method even if relatively large amounts of sodium chloride are present. If the nitrate content is very low and the salt very high, for instance, I part per million of nitrate and I per cent $\mathrm{NaCl}$, determinations were subject to serious errors, due to loss of nitrates and discoloration of the solution. In cases of very low nitrate and high salt content, evaporation of the solution to its proper concentration should be performed at a much reduced
TABLE I $50 \mathrm{cc}$. Solution in Sample $1.5 \mathrm{cc}$. Sulfuric Acid Added 2 cc. Phenoldisulfonic Acid Added Theoretical Actual Reading Change

\begin{tabular}{|c|c|c|c|}
\hline $\begin{array}{l}\text { Nitric } \\
\text { Nitrogen } \\
\text { P. p. m. }\end{array}$ & $\begin{array}{l}\text { Theoretical } \\
\text { Amount in cc. } \\
\text { of Standard }\end{array}$ & $\begin{array}{l}\text { ACTUAL READING } \\
\text { in cc. of } \\
\text { Standard }\end{array}$ & $\begin{array}{c}\text { Change } \\
\text { IN } \\
\text { TINT }\end{array}$ \\
\hline 1 & 50 & 49 & None \\
\hline I & 50 & 50 & None \\
\hline 2 & 100 & 100 & None \\
\hline 2 & 100 & 98 & None \\
\hline 5 & 500 & 500 & None \\
\hline 5 & 500 & 500 & None \\
\hline 20 & 1000 & 1000 & None \\
\hline 20 & 1000 & 1020 & None \\
\hline
\end{tabular}

TABLE II

$50 \mathrm{cc}$. Solution in Sample Theoret- Amount

\begin{tabular}{|c|c|c|c|c|c|}
\hline $\begin{array}{l}\text { Nitric } \\
\text { Nitro- } \\
\text { GEN } \\
\text { P. p.m. }\end{array}$ & $\begin{array}{c}\mathrm{NaCl} \\
\text { Added } \\
\text { mg. }\end{array}$ & $\begin{array}{l}\text { Per cent } \\
\text { NaCl } \\
\text { Present }\end{array}$ & $\begin{array}{l}\text { Theoret- } \\
\text { ical } \\
\text { Amount } \\
\text { in Cc. of } \\
\text { Standard }\end{array}$ & $\begin{array}{l}\text { Amount } \\
\text { Re. } \\
\text { covered } \\
\text { (Cc. of } \\
\text { Stan.) }\end{array}$ & $\begin{array}{c}\text { ChaNGE } \\
\text { IN } \\
\text { TINT }\end{array}$ \\
\hline 1 & 100 & 0.1 & 50 & 50 & None \\
\hline 1 & 100 & 0.1 & 50 & 50 & None \\
\hline 1 & 250 & 0.25 & 50 & 50 & None \\
\hline 1 & 250 & 0.25 & 50 & 48 & None \\
\hline 1 & 500 & 0.50 & 50 & 49 & None \\
\hline 1 & 500 & 0.50 & 50 & 50 & None \\
\hline 1 & 750 & 0.75 & 50 & 50 & Slightly colored \\
\hline 1 & 750 & 0.75 & 50 & 46 & Colored \\
\hline 1 & 1000 & 1.00 & 50 & 35 & Badly colored \\
\hline 1 & 1000 & 1.00 & 50 & 30 & Badly colored \\
\hline 5 & 500 & 0.50 & 250 & 250 & None \\
\hline 5 & 500 & 0.50 & 250 & 250 & None \\
\hline 10 & 1000 & 1.00 & 500 & 500 & None \\
\hline 10 & 1000 & 1.00 & 500 & 500 & None \\
\hline
\end{tabular}

temperature and preferably under partial vacuum, in order to reduce the action of acids on the salts.

\section{SUMMARY}

I-A satisfactory modification of the phenoldisulfonic acid method of nitrate determination in presence of chloride salts has been found.

II-Total evaporation of the solution to dryness can be obviated by the use of concentrated sulfuric acid, which is added to the aqueous extract.

III-The addition of sulfuric acid and phenoldisulfonic acid to the aqueous solution prevents the loss of nitrates, which in the old method was due to the action of acid added to the dry salt after evaporation to dryness had been accomplished.

IV-The temperature at which the final evaporation and concentration of the aqueous solution is performed should not exceed $70^{\circ} \mathrm{C}$.

SOIL CHEMISTRY LABORATORY

UNIVERSiTY OF CALIFORNIA, BERKELEY

\section{A NOTE ON THE PHENOLSULFONIC ACID METHOD FOR NITRATES IN WATERS HIGH IN MAGNESIUM SALTS}

By M. Starr Nichols

Received February 28, 1917

In the phenolsulfonic acid method for the determination of nitrates in water supplies, as given in the "Standard Methods of Water Analysis of the American Public Health Association," no provision is made for the removal of the hydroxides of magnesium and iron which may form on the addition of the alkali hydroxide used to neutralize the excess phenolsulfonic acid. In this laboratory, until recently, the colored solution containing the nitrated sulfonic acid has been filtered to remove these hydroxides and the filter paper subsequently washed.

In the absence of the hydroxide of iron, the filtration may be dispensed with and the color read immediately if a quantity of an ammonium salt is added to hold the magnesium in solution. There are two 